\title{
The role of bilirubin in diabetes, metabolic syndrome, and cardiovascular diseases
}

\section{Libor Vítek *}

Fourth Department of Internal Medicine, and Institute of Medical Biochemistry and Laboratory Diagnostics, First Faculty of Medicine, Charles University in Prague, Prague, Czech Republic

\section{Edited by:}

Jaime Kapitulnik, The Hebrew University of Jerusalem, Israel

\section{Reviewed by:}

Shlomo Sasson, The Hebrew University of Jerusalem, Israel Karl Walter Bock, University of Tübingen, Germany

\section{${ }^{*}$ Correspondence:}

Libor Vitek, Central Research

Laboratories, Institute of Medical Biochemistry and Laboratory

Diagnostics, First Faculty of

Medicine, Charles University in

Prague, Na Bojišti 3, 12808 Prague 2,

Czech Republic.

e-mail:vitek@cesnet.cz
Bilirubin belongs to a phylogenetically old superfamily of tetrapyrrolic compounds, which have multiple biological functions. Although for decades bilirubin was believed to be only a waste product of the heme catabolic pathway at best, and a potentially toxic compound at worst; recent data has convincingly demonstrated that mildly elevated serum bilirubin levels are strongly associated with a lower prevalence of oxidative stress-mediated diseases. Indeed, serum bilirubin has been consistently shown to be negatively correlated to cardiovascular diseases (CVD), as well as to CVD-related diseases and risk factors such as arterial hypertension, diabetes mellitus, metabolic syndrome, and obesity. In addition, the clinical data are strongly supported by evidence arising from both in vitro and in vivo experimental studies. This data not only shows the protective effects of bilirubin per se; but additionally, of other products of the heme catabolic pathway such as biliverdin and carbon monoxide, as well as its key enzymes (heme oxygenase and biliverdin reductase); thus, further underlining the biological impacts of this pathway. In this review, detailed information on the experimental and clinical evidence between the heme catabolic pathway and CVD, and those related diseases such as diabetes, metabolic syndrome, and obesity is provided. All of these pathological conditions represent an important threat to human civilization, being the major killers in developed countries, with a steadily increasing prevalence. Thus, it is extremely important to search for novel markers of these diseases, as well as for novel therapeutic modalities to reverse this unfavorable situation. The heme catabolic pathway seems to fulfill the criteria for both diagnostic purposes as well as for potential therapeutical interventions.

Keywords: bilirubin, biliverdin, biliverdin reductase, cardiovascular diseases, diabetes, heme oxygenase, metabolic syndrome, UGT1A1

\section{INTRODUCTION}

Bilirubin belongs to the superfamily of tetrapyrrolic compounds, which is one of the most highly conserved groups of molecules in nature. Tetrapyrroles have evolved to have pluripotent functions, including light harvesting in plants; as well as other roles in plants as well as in humans: chronobiology, energy generation, transport, and homeostasis of oxygen by hemoglobins and myoglobin - to mention only a few of them. Although for decades bilirubin was believed to be a potentially toxic metabolite of heme catabolism, in particular for central nervous system, data from the last few decades clearly demonstrates that this tetrapyrrolic compound might also have numerous other beneficial effects for the human body, including the scavenging of overproduced reactive oxygen species, anti-inflammatory actions, or direct effects upon cell signaling.

Bilirubin is the end product of heme catabolism in the systemic circulation. It is formed by the action of heme oxygenase (HMOX), an enzyme that splits cyclic tetrapyrrole heme into biliverdin, carbon monoxide, and ferrous iron. Biliverdin is subsequently reduced to bilirubin by biliverdin reductase (BLVRA). HMOX exists in two isoforms: HMOX1, a highly inducible isoform responsible for reactions of acute phase immediate response against oxidative stress, and a constitutive isoenzyme HMOX2, playing important roles in the brain and testes. The third member of the HMOX family (HMOX3) has also been described, but it is generally believed that HMOX3 is only represented by a pseudogene, with no coding function (Hayashi et al., 2004). Nevertheless, in light of the recent discoveries of the possible regulating functions of pseudogenes (Pink et al., 2011), it is possible that HMOX3 might also have biological effects by contributing to gene regulation.

Bilirubin, as a non-polar molecule, is solubilized in the vascular bed by binding to albumin. When reaching the liver, it is actively transported by the basolateral OATP transporter, solubilized in the cytoplasm by binding to specific binding proteins, and subsequently conjugated by the action of bilirubin UDPglucuronosyltransferase (UGT1A1) with two molecules of glucuronic acid. Bisglucuronosyl bilirubin is then actively secreted into bile and proceeds into the intestinal lumen, where it undergoes further metabolic changes. From the metabolic point of view, there are several crucial enzymatic steps (in particular those catalyzed by HMOX1, BLVRA, and UGT1A1 enzymes) which play an 
important role in bilirubin homeostasis with subsequent impacts on the risk of metabolic diseases, including cardiovascular diseases (CVD), diabetes, metabolic syndrome, arterial hypertension, and obesity.

Serum bilirubin concentrations are affected by many factors including cigarette smoking, gender, fasting, intake of numerous drugs and/or plant products, altitude, race, and age (for review see Vítek and Schwertner, 2007b). All these factors are likely to influence biological impact of bilirubin on human body.

\section{BIOLOGICAL PROPERTIES OF BILIRUBIN}

Bilirubin has been recognized as a substance with potent antioxidant properties. The first report on the antioxidant effects of bilirubin was published as early as 1954 (Bernard et al., 1954), however, it took several more decades until the antioxidant properties of bilirubin attracted major scientific attention (Stocker et al., 1987). Indeed, bilirubin has been shown to be more effective at protecting lipids from oxidation than the water-soluble antioxidants such as glutathione, which primarily protect proteins from oxidation (Sedlak et al., 2009). However, bilirubin has also been demonstrated to be almost 30 times more potent toward the prevention of LDL oxidation compared to a vitamin E analog, Trolox, which represents a lipid-soluble antioxidant substance (Wu et al., 1994). Even more importantly, serum bilirubin has been demonstrated to be a major contributor to the total antioxidant capacity in blood plasma (Frei et al., 1988). Additionally, bilirubin has been proven to have anti-inflammatory properties (for review see Vítek and Schwertner, 2007b). Bilirubin inhibited tumor necrosis factor $\alpha$-induced up-regulation of E-selectin, vascular cell adhesion molecule-1 (VCAM-1), and intercellular adhesion molecule (ICAM-1) in vitro (Mazzone et al., 2009). The negative association between serum bilirubin levels and soluble forms of CD40 ligand and P-selectin which have also been demonstrated in in vivo study on subjects with Gilbert syndrome (Tapan et al., 2009). Bilirubin has also been shown to significantly interfere with the complement system, with all of the possible protective consequences (reviewed in Basiglio et al., 2010). Consistent with this data, several studies have demonstrated a negative relationship between serum bilirubin and C-reactive protein levels (Vítek et al., 2007a; Hwang et al., 2011; Yoshino et al., 2011). In addition, the modulatory effects of bilirubin on $\mathrm{T}$ regulatory cell differentiation were recently reported (Rocuts et al., 2010), further underlining the protective role of bilirubin in the pathogenesis of chronic inflammatory as well as in autoimmune conditions.

\section{NEGATIVE ASSOCIATION BETWEEN BILIRUBIN AND CARDIOVASCULAR DISEASES}

The first report of a negative relationship between serum bilirubin levels and coronary artery disease was published as early as 1994 (Schwertner et al., 1994). Since then, numerous studies have been published, which have consistently demonstrated that subjects with lower bilirubin levels are at increased risk of both coronary and peripheral atherosclerotic disease (for reviews see recent papers; Vítek and Schwertner, 2007b; Schwertner and Vítek, 2008; Vítek and Ostrow, 2009; Lin et al., 2010). Serum bilirubin concentrations were also found to be negatively related to coronary artery calcification (Tanaka et al., 2009), and also to ischemic stroke (Kimm et al., 2009); all consistent with our own data which demonstrated a marked postponement in the progression of the intimo-medial thickness of carotid arteries in hyperbilirubinemic subjects with Gilbert syndrome, when compared to normobilirubinemic individuals (Vítek et al., 2006). In addition, our meta-analysis of studies focused on the association between CVD and bilirubin, involving almost 15,000 men, showed that each $1.0 \mu \mathrm{mol} / \mathrm{L}$ increase in serum bilirubin was associated with a $6.5 \%$ decrease in CVD risk (Novotný and Vítek, 2003). The same association was also reported in a recent Taiwanese prospective study on patients with cardiac X syndrome followed for 5 years, in which patients with the lowest serum bilirubin levels had a higher incidence of non-fatal myocardial infarction, ischemic stroke, rehospitalization for unstable angina, and coronary revascularization procedures (Huang et al., 2010).

Logically, the opposite relationship is also true, i.e., subjects with moderately elevated levels of serum bilirubin, such as those with Gilbert syndrome, are at decreased risk of CVD (Vítek et al., 2002).

Although the association of serum bilirubin levels and CVD has been known for almost two decades, the relationship between bilirubin and other players of the heme catabolic pathway, as well as pathologic conditions such as metabolic syndrome and/or diabetes has only been investigated in the last few years.

\section{HEME OXYGENASE AND DIABETES - EXPERIMENTAL EVIDENCE}

Diabetes mellitus, the hallmark of which consists of elevated plasma glucose, is consistently associated with increased oxidative stress, as well as enhanced formations of advanced glycation end products (AGEs; Yamagishi et al., 2011). Overproduction of oxidizing molecules results in the progressive loss of pancreatic $\beta$-cells, depleting insulin levels. However, also numerous other mechanisms contributing to the pathogenesis of diabetes play an important pathogenic role, including reduction of the adiponectin levels (Soares et al., 2005), interference with insulin signaling, endothelial dysfunction, or direct damages of the endothelial wall (Unoki and Yamagishi, 2008; Potenza et al., 2009; Giacco and Brownlee, 2010). Thus, it is not surprising that HMOX1, as a key antioxidant enzyme, has consistently been shown to protect from the development of diabetes (for review see Ndisang, 2010). The mechanisms by which HMOX1 mediated these effects are pluripotent, and apart from the antioxidant action, HMOX1 also directly affects glucose metabolism, which might be due to the presence of a binding site for a glucocorticoid-responsive element in the HMOX1 gene promoter (Lavrovsky et al., 1996). In fact, HMOX1 was shown to stimulate insulin production in experimental animal models (Ndisang, 2010), at least partially, via the release of carbon monoxide (Henningsson et al., 1999), which is an immediate product of HMOX. Indeed, HMOX1 induction by hemin has been demonstrated to improve insulin signaling and glucose metabolism, and to have lowered insulin resistance in various animal models, including those of streptozotocin-induced diabetes (Ndisang and Jadhav, 2009a), insulin-resistant type 2 diabetes (Ndisang and Jadhav, 2009b), primary hyperaldosteronism (Ndisang and Jadhav, 2010a), as well as essential hypertension (Ndisang et al., 2010b). Apart from an improvement of insulin 
sensitivity, HMOX1 induction was also reported to reduce visceral and subcutaneous obesity in diabetic and obese mice (Li et al., 2008; Nicolai et al., 2009; Burgess et al., 2010) through mechanisms involving the attenuation of the inflammatory processes, as well as modulation of PPAR $\gamma$ signaling (Ndisang, 2010). Furthermore, chronic HMOX1 induction was shown to increase metabolic turnover, heat production, and physical activity in an experimental model of obesity (Csongradi et al., 2012), suggesting the complexity of the beneficial effects of HMOX1 induction upon these metabolic disorders.

\section{HEME OXYGENASE AND DIABETES - CLINICAL EVIDENCE}

Experimental data on the role of HMOX in the pathogenesis of diabetes, metabolic syndrome, and obesity are also supported by the clinical evidence. Plasma concentrations of HMOX1 have been demonstrated to strongly correlate with type 2 diabetes mellitus (Bao et al., 2010b). In fact, subjects in the highest quartile of HMOX1 plasma levels had more than an 8X higher risk for development of type 2 diabetes, compared to the lowest quartile (Bao et al., 2010b). In this study, the HMOX1 plasma level might reflect increased oxidative stress preceding the expression of diabetes. In addition, it is known that high glucose exposure leads to HMOX1 induction (Jonas et al., 2003; Won et al., 2006), which also might account for the observed phenomenon. On the other hand, the same authors recently published a meta-analysis of six studies focused on the role of HMOX1 promoter gene variants and the risk of diabetes, covering almost 2,000 diabetic patients and 3,500 controls. These results revealed that subjects carrying longer (GT)n repeats in the HMOX1 gene promoter (associated, nevertheless, with decreased HMOX1 activity), had an increased risk of type 2 diabetes (Bao et al., 2010a). In addition to the effect on diabetes risk, diabetic subjects with the L/L genotype had an almost threefold increase in CVD risk, even after controlling for conventional risk factors in one of the studies involved in the reported meta-analysis (Chen et al., 2008). Further detailed clinical studies are needed to elucidate all of the mechanisms related to the roles of HMOX in the risks of development of diabetes.

\section{BILIVERDIN REDUCTASE AND DIABETES - EXPERIMENTAL EVIDENCE AND POSSIBLE CLINICAL IMPLICATIONS}

Biliverdin reductase, similarly as HMOX, is an evolutionarily conserved enzyme, responsible for the hydrogenation of biliverdin on bilirubin. Besides that, BLVRA has multiple other functions affecting cell signaling, modulating immune system response, and also exerting substantial metabolic effects (Maines, 2005; Kapitulnik and Maines, 2009; Wegiel et al., 2011). BLVRA also serves as a unique serine/threonine/tyrosine kinase, significantly modulating (among other molecules) the phosphorylation of the insulin receptor substrate-1, as well as other insulin/IGF-1 signaling pathway targets (Kapitulnik and Maines, 2009). As a result, BLVRA diminishes insulin signaling, and acts as a negative regulator of glucose uptake (Lerner-Marmarosh et al., 2005). BLVRA also binds to the p85 regulatory subunit of PI3K/Akt (Pachori et al., 2007), a mechanism which might also lead to improved insulin sensitivity (Terauchi et al., 1999). Based upon this data, small BLVRA-based peptides which activate the insulin receptor signaling axis have been suggested as possible therapeutics to combat insulin resistance in diabetic patients (Lerner-Marmarosh et al., 2008).

Not only BLVRA itself, but also the products of its basic enzymatic activity, biliverdin (and consequently bilirubin), might significantly contribute to protection from diabetic complications. Oral administration of biliverdin to $d b / d b$ mice partially prevented a worsening of hyperglycemia and glucose intolerance (Ikeda et al., 2011), as well as diabetic nephropathy in these animals, principally via inhibition of oxidative stress-induced damage, mediated by the interference with the NADPH oxidase pathway (Fujii et al., 2010). Biliverdin-treated animals had less albuminuria, and complete protection against the progression of mesangial expansion, accompanied by normalization of transforming growth factor- $\beta 1$ and the expression of fibronectin (Fujii et al., 2010).

There are no clinical data on the role of BLVRA/biliverdin in diabetes, metabolic syndrome, or obesity. Only recently, a paper describing the effect of a BLVRA gene variant (rs699512) on the risk of essential hypertension has just been reported (Lin et al., 2011). Detailed studies are certainly needed to fully elucidate the clinical relevance of the experimental findings discussed.

\section{BILIRUBIN AND DIABETES - EXPERIMENTAL EVIDENCE}

It is not surprising that bilirubin, a subsequent reduction product of biliverdin, also has salutary effects in terms of the prevention of diabetes mellitus and its complications. In addition, bilirubin was also reported to provide protection against metabolic syndrome, and to be negatively associated with overweight and obesity.

In fact, in a manner similar to biliverdin substantially improving renal pathology in $d b / d b$ mice, specifically via inhibition of NADPH oxidase (as discussed above), a practically identical effect was observed in hyperbilirubinemic Gunn rats exposed to streptozocin (Fujii et al., 2010). Compared to their diabetic normobilirubinemic heterozygous siblings, diabetic Gunn rats developed less albuminuria, exhibited practically normal urinary levels of 8-hydroxy-2'-deoxyguanosine (8-OHdG), as well as 8epi-prostaglandin F2 $\alpha$ levels; both markers of systemic oxidative stress. Additionally, expression of NADPH oxidase was markedly attenuated in the kidneys of diabetic Gunn rats, who also exhibited complete inhibition of mesangial expansion when compared to normobilirubinemic diabetic controls (Fujii et al., 2010). Consistent with this data, Korean researchers reported substantial resistance of hyperbilirubinemic Gunn rats to developing diabetes after intraperitoneal exposure to streptozocin, compared to their normobilirubinemic littermates (Fu et al., 2010). Markers of diabetes, such as fasting blood glucose and HbAlc levels were much less pronounced in Gunn rats; on the other hand, insulin secretion by the pancreatic islets was preserved in hyperbilirubinemic animals. In addition, concentrations as low as $1.7 \mu \mathrm{mol} / \mathrm{L}$ bilirubin prevented streptozocin-induced apoptosis in rat insulinoma cell culture; significantly supporting the in vivo data (Fu et al., 2010).

\section{BILIRUBIN, DIABETES, METABOLIC SYNDROME, AND OBESITY - CLINICAL EVIDENCE}

Negative associations between serum bilirubin concentrations and abnormal glucose tolerance tests were reported as early as 1996 (Ko et al., 1996). Since then, numerous clinical studies evaluating the possible associations between serum/plasma bilirubin levels 
and the risk of diabetes (and its complications) have been published. Inoguchi et al. (2007) first indicated that diabetic patients who have concomitant Gilbert syndrome have a lower prevalence rate of vascular complications, compared to normobilirubinemic diabetics. Although not specifically mentioned in their study, the prevalence of Gilbert syndrome among more than 5,000 consecutive diabetics was at least three times lower than would be expected in the general population. This data is in line with our observation of low prevalence of diabetes in subjects with $(\mathrm{TA})_{7}$ promoter variation in UGT1A1 responsible for systemic bilirubin homeostasis (Jirásková et al., 2011), and with low levels of AGEs in Gilbert syndrome subjects, compared to the normobilirubinemic population (Kalousová et al., 2005). Furthermore, low serum bilirubin levels were identified as an important predictor of CVD in Type 2 diabetes patients receiving haemodialysis (Fukui et al., 2011). Just recently, another group of Japanese investigators reported in their cross-sectional study on more than 3,000 participants, that compared to subjects within the lowest bilirubin quartile, those with the highest bilirubin levels had a four times lower prevalence of diabetic retinopathy (Yasuda et al., 2011). In a large Korean crosssectional study on almost 94,000 subjects, high serum bilirubin was also found to be associated with the reduced risk of diabetes mellitus and diabetic nephropathy (Han et al., 2010). Higher serum bilirubin levels were also shown to protect from diabetes mellitus in the US National Health and Nutrition Examination Survey (NHANES) on almost 16,000 subjects. In this study, subjects with a bilirubin level above $10 \mu \mathrm{mol} / \mathrm{L}$ had $20 \%$ less risk of developing diabetes, compared to those with bilirubin levels below this cut-off value, even after multiple adjustments (Cheriyath et al., 2010).

Similarly, additional studies have supported the protective effects of bilirubin on both clinical and laboratory outcomes of diabetic subjects. Serum bilirubin concentrations were demonstrated to be negatively associated with albuminuria in patients with type 2 diabetes (Fukui et al., 2008), HbAlc levels (being an independent risk factor of CVD) in Japanese populations (Oda, 2010; Oda and Kawai, 2010; Ohnaka et al., 2010); additionally, with both insulin resistance and prevalence rate of the metabolic syndrome among children and adolescents (Lin et al., 2009a), as well as in adult populations (Kwon et al., 2011; Wu et al., 2011). Consistent with this data, low prevalence of metabolic syndrome in subjects with phenotypic Gilbert syndrome was described in a recent large Korean study on more than 12,000 participants (Choi et al., 2011).

In line with these negative relationships between serum bilirubin levels and metabolic syndrome, a negative association between bilirubin levels and abdominal obesity per se has been shown in several recent studies (Bhuiyan et al., 2008; Lin et al., 2009a; Choi et al., 2011; Kwon et al., 2011; Wu et al., 2011). Since weight reduction is known to reduce several cardiovascular risk factors, it is important to note that each one percent decrease in weight loss was associated with a linear increase in serum bilirubin concentration (Andersson et al., 2009). The close relationship between serum bilirubin levels and the UGT1A1 gene promoter variants, responsible for manifestation of Gilbert syndrome in Asians, and the risk of non-alcoholic fatty liver disease (a condition commonly associated with obesity and metabolic syndrome) was recently demonstrated in Taiwanese children (Lin et al., 2009b); further underlining the importance of the heme catabolic pathway in the pathogenesis of obesity, metabolic syndrome, diabetes mellitus and its complications.

\section{PHARMACOLOGIC AND/OR NUTRACEUTIC INTERVENTIONS}

Interventions which induce HMOX1 and/or BLVRA, or those that inhibit UGT1A1 activities might be effective in increasing serum and tissue bilirubin concentrations, as well as in modulating signaling pathways involved in energy homeostasis.

Heme oxygenase 1, as a highly inducible enzyme, which can be upregulated by many common drugs routinely used in clinical medicine (Bach, 2005), including non-steroidal antiinflammatory drugs, hypolipidemics (Muchová et al., 2007; Wu et al., 2012), PPAR $\alpha$ agonists, certain immunosuppressive drugs, to mention just a few. It is likely that at least part of their therapeutic action might be mediated via induction of HMOX1. The therapeutic potential of HMOX1 induction is also supported by recent experimental data demonstrating that chronic HMOX1 induction lowers body weight, corrects hyperglycemia and hyperinsulinemia, as well as increases oxygen consumption, heat production, and activity in obese mice (Csongradi et al., 2012).

Based on recent data, it also becomes evident that BLVRA might have great therapeutic implications (Maines, 2010). In fact, small residue peptides designed according to the primary structure of BLVRA were shown to block important pathways implicated in the pathogenesis of diabetes, including the inhibition of the MAPK (Lerner-Marmarosh et al., 2008) and TNF- $\alpha /$ PKC $\zeta /$ NF- $\kappa$ B pathways (Lerner-Marmarosh et al., 2007), as well as the inhibition of activation and membrane translocation of PKC- $\beta$ II (Maines et al., 2007). There are also pharmaceuticals capable of a partial inhibition of UGT1A1, which in turn result in a mild elevation of systemic bilirubin levels. Among the substances having UGT1A1 inhibiting activity is a uricosuric drug probenecid (McCarty, 2007), and also the antiviral drug atazanavir (Dekker et al., 2011). In fact, atazanavir has been demonstrated to improve endothelial function in patients with type 2 diabetes mellitus, most likely due to its bilirubin-increasing activities (Dekker et al., 2011).

However, the heme catabolic pathway might also be potentiated through non-pharmacologic means, and its salutary effects can, for instance, be mimicked by tetrapyrollic compounds widely occurring in plants and algae. There are numerous natural HMOX1 inducers originating from plants, including polyphenols, but also compounds such as curcumin, or silymarin (Bonifaz et al., 2009). Indeed, curcumin was reported to increase insulin secretion from rat-isolated pancreatic islets via HMOX1 induction (Abdel Aziz et al., 2010), as well as to improve clinical and laboratory markers of experimental diabetes (Gutierres et al., 2011; Soetikno et al., 2011); the same effect was also demonstrated for silymarin-treated diabetic rats (Vessal et al., 2010). Although the action of both compounds is certainly multifactorial, HMOX1 induction seems to play an important role in their anti-diabetic effects.

It is also tempting to speculate that oral supplementation with nutraceuticals containing plant tetrapyrolles, such as phycocyanobilins (Lee et al., 2008; Moura et al., 2011), or their increased consumption in the form of natural foods (Tonstad et al., 2009) might be used as a novel approach of the chemoprevention of obesity, metabolic syndrome, and diabetes. 


\section{CONCLUDING REMARKS}

In this review, the experimental as well as clinical studies on the associations between CVD, diabetes mellitus, metabolic syndrome, and obesity with the heme catabolic pathway have been discussed. These studies unanimously show that low serum bilirubin concentrations are associated with an increased risk of these pathologic conditions; whereas, mildly elevated serum bilirubin levels provide protection. Moreover, it is clear that apart from the direct beneficial effects of bile pigments, the enzymes HMOX1 and BLVRA also play an important role in the development of these metabolic diseases. Based on recent data, it seems that there is a therapeutical potential to modulate HMOX1, BLVRA, and UGT1A1 activities, and/or mildly increase bilirubin levels (or its analogs) in the systemic circulation

\section{REFERENCES}

Abdel Aziz, M. T., El-Asmar, M. F., El Nadi, E. G., Wassef, M. A., Ahmed, H. H., Rashed, L. A., Obaia, E. M., Sabry, D., Hassouna, A. A., and Abdel Aziz, A. T. (2010). The effect of curcumin on insulin release in ratisolated pancreatic islets. Angiology 61, 557-566.

Andersson, C., Weeke, P., Fosbol, E. L., Brendorp, B., Kober, L., Coutinho, W., Sharma, A. M., Van Gaal, L., Finer, N., James, W. P., Caterson, I. D., Rode, R. A., and Torp-Pedersen, C. (2009). Acute effect of weight loss on levels of total bilirubin in obese, cardiovascular high-risk patients: an analysis from the lead-in period of the sibutramine cardiovascular outcome trial. Metab. Clin. Exp. 58, 1109-1115.

Bach, F. H. (2005). Heme oxygenase-1: a therapeutic amplification funnel. FASEB J. 19, 1216-1219.

Bao, W., Song, F., Li, X., Rong, S., Yang, W., Wang, D., Xu, J., Fu, J., Zhao, Y., and Liu, L. (2010a). Association between heme oxygenase-1 gene promoter polymorphisms and type 2 diabetes mellitus: a HuGE review and metaanalysis. Am. J. Epidemiol. 172, 631-636.

Bao, W., Song, F., Li, X., Rong, S., Yang, W., Zhang, M., Yao, P., Hao, L., Yang, N., Hu, F. B., and Liu, L. (2010b). Plasma heme oxygenase-1 concentration is elevated in individuals with type 2 diabetes mellitus. PLoS ONE 5, e12371. doi:10.1371/journal.pone.0012371

Basiglio, C. L., Arriaga, S. M., Pelusa, F., Almara, A. M., Kapitulnik, J., and Mottino, A. D. (2010). Complement activation and disease: protective effects of hyperbilirubinaemia. Clin. Sci. 118, 99-113.

Bernard, K., Ritzel, G., and Steiner, K. U. (1954). Über eine biologische bedeutung der gallenfarbstoffe: bilirubin und biliverdin als antioxydantien für das vitamin $\mathrm{A}$ und die essentiellen Fettsäuren. Helv. Chim. Acta 37, 306-313.

Bhuiyan, A. R., Srinivasan, S. R., Chen, W., Sultana, A., and Berenson, G. S. (2008). Association of serum bilirubin with pulsatile arterial function in asymptomatic young adults: the Bogalusa Heart Study. Metab. Clin. Exp. 57, 612-616.

Bonifaz, V., Shan, Y., Lambrecht, R. W., Donohue, S. E., Moschenross, D. and Bonkovsky, H. L. (2009). Effects of silymarin on hepatitis $\mathrm{C}$ virus and haem oxygenase-1 gene expression in human hepatoma cells. Liver Int. 29, 366-373.

Burgess, A., Li, M., Vanella, L., Kim, D. H., Rezzani, R., Rodella, L., Sodhi, K., Canestraro, M., Martasek, P., Peterson, S. J., Kappas, A., and Abraham, N. G. (2010). Adipocyte heme oxygenase-1 induction attenuates metabolic syndrome in both male and female obese mice. Hypertension 56, 1124-1130.

Chen, Y. H., Chau, L. Y., Chen, J. W., and Lin, S. J. (2008). Serum bilirubin and ferritin levels link between heme oxygenase-1 gene promoter polymorphism and susceptibility to coronary artery disease in diabetic patients. Diabetes Care 31, 1615-1620.

Cheriyath, P., Gorrepati, V. S., Peters, I., Nookala, V., Murphy, M. E., Srouji, N., and Fischman, D. (2010). High total bilirubin as a protective factor for diabetes mellitus: an analysis of NHANES data from 1996-2006. J. Clin. Med. Res. 2, 201-206.

Choi, S. H., Yun, K. E., and Choi, H. J. (2011). Relationships between serum total bilirubin levels and metabolic syndrome in Korean adults. Nutr. Metab. Cardiovasc. Dis. doi:10.1016/j.numecd.2011.03.001. [Epub ahead of print].

Csongradi, E., Docarmo, J. M., Dubinion, J. H., Vera, T., and Stec, D. E. (2012). Chronic HO-1 induction with cobalt protoporphyrin (CoPP) treatment increases oxygen

to suppress pathways leading to the development of diabetes and its complications. Obviously, detailed studies to explore this potential further appear warranted, and will definitely provide much needed evidence that the whole heme catabolic pathway is also likely beneficial for this group of metabolic diseases.

\section{ACKNOWLEDGMENTS}

This work was partly supported by grants SVV-2011-262513 and LH11030, from the Czech Ministry of Education; grant NS 9770-4-28 from the Czech Ministry of Health, grant Prvouk P25/LF1/2 from the Charles University in Prague and grant CZ:GA CR:P206/11/0836 from the Research Granting Agency of the Czech Republic.

consumption, activity, heat production and lowers body weight in obese melanocortin-4 receptor-deficien mice. Int. J. Obes. 36, 244-253.

Dekker, D., Dorresteijn, M. J., Pijnenburg, M., Heemskerk, S. Rasing-Hoogveld, A., Burger, D. M., Wagener, F. A., and Smits, P. (2011). The bilirubin-increasing drug atazanavir improves endothelial function in patients with type 2 diabetes mellitus. Arterioscler. Thromb. Vasc. Biol. 31, 458-463.

Frei, B., Stocker, R., and Ames, B. N. (1988). Antioxidant defenses and lipid peroxidation in human blood plasma. Proc. Natl. Acad. Sci. U.S.A. 85, 9748-9752.

Fu, Y. Y., Kang, K. J., Ahn, J. M., Kim, H. R., Na, K. Y., Chae, D. W., Kim, S. and Chin, H. J. (2010). Hyperbilirubinemia reduces the streptozotocininduced pancreatic damage through attenuating the oxidative stress in the Gunn rat. Tohoku J. Exp. Med. 222, 265-273.

Fujii, M., Inoguchi, T., Sasaki, S., Maeda, Y., Zheng, J., Kobayashi, K., and Takayanagi, R. (2010). Bilirubin and biliverdin protect rodents against diabetic nephropathy by downregulating $\mathrm{NAD}(\mathrm{P}) \mathrm{H}$ oxidase. Kidney Int 78, 905-919.

Fukui, M., Tanaka, M., Shiraishi, E., Harusato, I., Hosoda, H., Asano, M., Hasegawa, G., and Nakamura, N. (2008). Relationship between serum bilirubin and albuminuria in patients with type 2 diabetes. Kidney Int. 74, 1197-1201.

Fukui, M., Tanaka, M., Yamazaki, M., Hasegawa, G., Nishimura, M., Iwamoto, N., Ono, T., Imai, S. and Nakamura, N. (2011). Low serum bilirubin concentration in haemodialysis patients with Type 2 diabetes. Diabet. Med. 28, 96-99.

Giacco, F., and Brownlee, M. (2010). Oxidative stress and diabetic complications. Circ. Res. 107, 1058-1070. Gutierres, V. O., Pinheiro, C. M., Assis, R. P., Vendramini, R. C.
Pepato, M. T., and Brunetti, I. L. (2011). Curcumin-supplemented yoghurt improves physiological and biochemical markers of experimental diabetes. Br. J. Nutr. 1-9. doi:10.1017/S0007114511005769. [Epub ahead of print].

Han, S. S., Na, K. Y., Chae, D. W., Kim, Y. S., and Chin, H. J. (2010). High serum bilirubin is associated with the reduced risk of diabetes mellitus and diabetic nephropathy. Tohoku J. Exp. Med. 221, 133-140.

Hayashi, S., Omata, Y., Sakamoto, H., Higashimoto, Y., Hara, T., Sagara, Y., and Noguchi, M. (2004). Characterization of rat heme oxygenase- 3 gene. Implication of processed pseudogenes derived from heme oxygenase2 gene. Gene 336, 241-250.

Henningsson, R., Alm, P., Ekstrom, P., and Lundquist, I. (1999). Heme oxygenase and carbon monoxide: regulatory roles in islet hormone release: a biochemical, immunohistochemical, and confocal microscopic study. Diabetes 48, 66-76.

Huang, S. S., Huang, P. H., Leu, H. B., Wu, T. C., Lin, S. J., and Chen, J. W. (2010). Serum bilirubin predicts long-term clinical outcomes in patients with cardiac syndrome $\mathrm{X}$. Heart 96, 1227-1232.

Hwang, H. J., Lee, S. W., and Kim, S. H. (2011). Relationship between bilirubin and C-reactive protein. Clin. Chem. Lab. Med. 49, 1823-1828.

Ikeda, N., Inoguchi, T., Sonoda, N., Fujii, M., Takei, R., Hirata, E., Yokomizo, H., Zheng, J., Maeda, Y., Kobayashi, K., and Takayanagi, R. (2011). Biliverdin protects against the deterioration of glucose tolerance in $\mathrm{db} / \mathrm{db}$ mice. Diabetologia 54 , 2183-2191.

Inoguchi, T., Sasaki, S., Kobayashi, K., Takayanagi, R., and Yamada, T. (2007). Relationship between Gilbert syndrome and prevalence of vascular complications in patients with diabetes. JAMA 298, 1398-1400. 
Jirásková, A., Jovanovská, J., Škrha, J., and Vítek, L. (2011). Association of low bilirubin levels and promoter variations in UGT1Al gene with diabetes mellitus type 2 (abstract). Hepatol. Int. 5, 37.

Jonas, J. C., Guiot, Y., Rahier, J., and Henquin, J. C. (2003). Haeme-oxygenase 1 expression in rat pancreatic beta cells is stimulated by supraphysiological glucose concentrations and by cyclic AMP. Diabetologia 46, 1234-1244.

Kalousová, M., Novotný, L., Zima, T., Braun, M., and Vítek, L. (2005). Decreased levels of advanced glycation end-products in patients with Gilbert syndrome. Cell. Mol. Biol.51, 387-392.

Kapitulnik, J., and Maines, M. D. (2009). Pleiotropic functions of biliverdin reductase: cellular signaling and generation of cytoprotective and cytotoxic bilirubin. Trends Pharmacol. Sci. 30, 129-137.

Kimm, H., Yun, J. E., Jo, J., and Jee, S. H. (2009). Low serum bilirubin level as an independent predictor of stroke incidence: a prospective study in Korean men and women. Stroke 40, 3422-3427.

Ko, G. T., Chan, J. C., Woo, J., Lau, E., Yeung, V. T., Chow, C. C., Li, J. K., So, W. Y., and Cockram, C. S. (1996). Serum bilirubin and cardiovascular risk factors in a Chinese population. J. Cardiovasc. Risk 3, 459-463.

Kwon, K. M., Kam, J. H., Kim, M. Y., Kim, M. Y., Chung, C. H., Kim, J. K., Linton, J. A., Eom, A., Koh, S. B., and Kang, H. T. (2011). Inverse association between total bilirubin and metabolic syndrome in rural korean women. J. Womens Health 20 , 963-969.

Lavrovsky, Y., Drummond, G. S., and Abraham, N. G. (1996). Downregulation of the human heme oxygenase gene by glucocorticoids and identification of 56b regulatory elements. Biochem. Biophys. Res. Commun. 218, 759-765.

Lee, E. H., Park, J. E., Choi, Y. J., Huh, K. B., and Kim, W. Y. (2008). A randomized study to establish the effects of spirulina in type 2 diabetes mellitus patients. Nutr. Res. Pract. 2, 295-300.

Lerner-Marmarosh, N., Miralem, T., Gibbs, P. E., and Maines, M. D. (2007). Regulation of TNF-alphaactivated PKC-zeta signaling by the human biliverdin reductase: identification of activating and inhibitory domains of the reductase. FASEB $J$. 21, 3949-3962.

Lerner-Marmarosh, N., Miralem, T., Gibbs, P. E., and Maines, M. D. (2008). Human biliverdin reductase is an ERK activator; $\mathrm{hBVR}$ is an ERK nuclear transporter and is required for MAPK signaling. Proc. Natl. Acad. Sci. U.S.A. 105, 6870-6875.

Lerner-Marmarosh, N., Shen, J., Torno, M. D., Kravets, A., Hu, Z., and Maines, M. D. (2005). Human biliverdin reductase: a member of the insulin receptor substrate family with serine/threonine/tyrosine kinase activity. Proc. Natl. Acad. Sci. U.S.A. 102, 7109-7114.

Li, M., Kim, D. H., Tsenovoy, P. L., Peterson, S. J., Rezzani, R., Rodella, L. F., Aronow, W. S., Ikehara, S., and Abraham, N. G. (2008). Treatment of obese diabetic mice with a heme oxygenase inducer reduces visceral and subcutaneous adiposity, increases adiponectin levels, and improves insulin sensitivity and glucose tolerance. Diabetes 57, 1526-1535.

Lin, J. P., Vítek, L., and Schwertner, H. A. (2010). Serum bilirubin and genes controlling bilirubin concentrations as biomarkers for cardiovascular disease. Clin. Chem. 56, 1535-1543,

Lin, L. Y., Kuo, H. K., Hwang, J. J., Lai, L. P., Chiang, F. T., Tseng, C. D., and Lin, J. L. (2009a). Serum bilirubin is inversely associated with insulin resistance and metabolic syndrome among children and adolescents. Atherosclerosis 203, 563-568.

Lin, Y. C., Chang, P. F., Hu, F. C., Chang, M. H., and Ni, Y. H. (2009b). Variants in the UGT1A1 gene and the risk of pediatric nonalcoholic fatty liver disease. Pediatrics 124, e1221-e1227.

Lin, R., Wang, X., Zhou, W., Fu, W., Wang, Y., Huang, W., and Jin, L. (2011). Association of a BLVRA common polymorphism with essential hypertension and blood pressure in Kazaks. Clin. Exp. Hypertens. 33, 294-298.

Maines, M. D. (2005). New insights into biliverdin reductase functions: linking heme metabolism to cell signaling. Physiology (Bethesda) 20, 382-389.

Maines, M. D. (2010). Potential application of biliverdin reductase and its fragments to modulate insulin/IGF1/MAPK/PI3-K signaling pathways in therapeutic settings. Curr. Drug Targets 11, 1586-1594.

Maines, M. D., Miralem, T., LernerMarmarosh, N., Shen, J., and Gibbs, P. E. (2007). Human biliverdin reductase, a previously unknown activator of protein kinase $\mathrm{C}$ betalI. J. Biol. Chem. 282, 8110-8122.

Mazzone, G. L., Rigato, I., Ostrow, J. D., Bossi, F., Bortoluzzi, A., Sukowati, C. H., Tedesco, F., and Tiribelli, C. (2009). Bilirubin inhibits the TNFalpha-related induction of three endothelial adhesion molecules. Biochem. Biophys. Res. Commun. 386, 338-344.

McCarty, M. F. (2007). "Iatrogenic Gilbert syndrome" - a strategy for reducing vascular and cancer risk by increasing plasma unconjugated bilirubin. Med. Hypotheses 69, 974-994.

Moura, L. P., Puga, G. M., Beck, W. R., Teixeira, I. P., Ghezzi, A. C., Silva, G. A., and Mello, M. A. (2011). Exercise and spirulina control non-alcoholic hepatic steatosis and lipid profile in diabetic Wistar rats. Lipids Health Dis. 10, 77.

Muchová, L., Wong, R. J., Hsu, M., Morioka, I., Vítek, L., Zelenka, J., Schroder, H., and Stevenson, D. K. (2007). Statin treatment increases formation of carbon monoxide and bilirubin in mice: a novel mechanism of in vivo antioxidant protection. Can. J. Physiol. Pharmacol. 85, 800-810.

Ndisang, J. F. (2010). Role of heme oxygenase in inflammation, insulin-signalling, diabetes and obesity. Mediators Inflamm. doi:10.1155/2010/359732. [Epub 2010 May 18].

Ndisang, J. F., and Jadhav, A. (2009a). Heme oxygenase system enhances insulin sensitivity and glucose metabolism in streptozotocininduced diabetes. Am. J. Physiol Endocrinol. Metab. 296, E829-E841.

Ndisang, J. F., and Jadhav, A. (2009b). Up-regulating the hemeoxygenase system enhances insulin sensitivity and improves glucose metabolism in insulin-resistant diabetes in GotoKakizaki rats. Endocrinology 150 2627-2636.

Ndisang, J. F., and Jadhav, A. (2010a). The heme oxygenase system attenuates pancreatic lesions and improves insulin sensitivity and glucose metabolism in deoxycorticosterone acetate hypertension. Am. J. Physiol. Regul. Integr. Comp. Physiol. 298, R211-R223.

Ndisang, J. F., Lane, N., Syed, N., and Jadhav, A. (2010b). Up-regulating the heme oxygenase system with hemin improves insulin sensitivity and glucose metabolism in adult spontaneously hypertensive rats. Endocrinology 151, 549-560.

Nicolai, A., Li, M., Kim, D. H., Peterson, S. J., Vanella, L., Positano, V., Gastaldelli, A., Rezzani, R., Rodella, L. F., Drummond, G., Kusmic, C. L'Abbate, A., Kappas, A., and Abraham, N. G. (2009). Heme oxygenase1 induction remodels adipose tissue and improves insulin sensitivity in obesity-induced diabetic rats. Hypertension 53, 508-515.

Novotný, L., and Vítek, L. (2003). Inverse relationship between serum bilirubin and atherosclerosis in men: a meta-analysis of published studies. Exp. Biol. Med. 228, 568-571.

Oda, E. (2010). Bilirubin is negatively associated with A1C independently of fasting plasma glucose, age, obesity, inflammation, hemoglobin, and iron in apparently healthy Japanese men and women. Diabetes Care 33, e131.

Oda, E., and Kawai, R. (2010). Bilirubin is negatively associated with hemoglobin a(1c) independently of other cardiovascular risk factors in apparently healthy Japanese men and women. Circ. J. 75, 190-195.

Ohnaka, K., Kono, S., Inoguchi, T., Yin, G., Morita, M., Adachi, M., Kawate, H., and Takayanagi, R. (2010). Inverse associations of serum bilirubin with high sensitivity C-reactive protein, glycated hemoglobin, and prevalence of type 2 diabetes in middle-aged and elderly Japanese men and women. Diabetes Res. Clin. Pract. 88, 103-110.

Pachori, A. S., Smith, A., McDonald, P., Zhang, L., Dzau, V. J., and Melo, L. G. (2007). Hemeoxygenase-1-induced protection against hypoxia/reoxygenation is dependent on biliverdin reductase and its interaction with PI3K/Akt pathway. J. Mol. Cell. Cardiol. 43, 580-592.

Pink, R. C., Wicks, K., Caley, D. P. Punch, E. K., Jacobs, L., and Carter, D. R. (2011). Pseudogenes: pseudofunctional or key regulators in health and disease? RNA. 17, 792-798.

Potenza, M. A., Gagliardi, S., Nacci, C., Carratu', M. R., and Montagnani, M. (2009). Endothelial dysfunction in diabetes: from mechanisms to therapeutic targets. Curr. Med. Chem. 16 94-112.

Rocuts, F., Zhang, X., Yan, J., Yue, Y., Thomas, M., Bach, F. H., Czismadia, E., and Wang, H. (2010). Bilirubin promotes de novo generation of $\mathrm{T}$ regulatory cells. Cell Transplant. 19, 443-451.

Schwertner, H. A., Jackson, W. G., and Tolan, G. (1994). Association of low serum concentration of bilirubin with increased risk of coronary artery disease. Clin. Chem. 40, $18-23$.

Schwertner, H. A., and Vítek, L. (2008). Gilbert syndrome, UGT1A1 $* 28$ allele, and cardiovascular disease risk: possible protective effects and therapeutic applications of bilirubin. Atherosclerosis 198, 1-11. 
Sedlak, T. W., Saleh, M., Higginson, D. S., Paul, B. D., Juluri, K. R., and Snyder, S. H. (2009). Bilirubin and glutathione have complementary antioxidant and cytoprotective roles. Proc. Natl. Acad. Sci. U.S.A. 106, 5171-5176.

Soares, A. F., Guichardant, M., Cozzone, D., Bernoud-Hubac, N., BouzaidiTiali, N., Lagarde, M., and Geloen, A. (2005). Effects of oxidative stress on adiponectin secretion and lactate production in 3T3-L1 adipocytes. Free Radic. Biol. Med. 38, 882-889.

Soetikno, V., Watanabe, K., Sari, F. R., Harima, M., Thandavarayan, R. A., Veeraveedu, P. T., Arozal, W., Sukumaran, V., Lakshmanan, A. P., Arumugam, S., and Suzuki, K. (2011). Curcumin attenuates diabetic nephropathy by inhibiting PKC-alpha and PKC-betal activity in streptozotocin-induced type I diabetic rats. Mol. Nutr. Food Res. 55, 1655-1665.

Stocker, R., Yamamoto, Y., McDonagh, A. F., Glazer, A. N., and Ames, B. N. (1987). Bilirubin is an antioxidant of possible physiological importance. Science 235, 1043-1046.

Tanaka, M., Fukui, M., Tomiyasu, K. I., Akabame, S., Nakano, K., Hasegawa, G., Oda, Y., and Nakamura, N. (2009). Low serum bilirubin concentration is associated with coronary artery calcification (CAC). Atherosclerosis 206, 287-291.

Tapan, S., Dogru, T., Tasci, I., Ercin, C. N., Ozgurtas, T., and Erbil, M. K. (2009). Soluble CD40 ligand and soluble P-selectin levels in Gilbert's syndrome: a link to protection against atherosclerosis? Clin. Biochem. 42,791-795.

Terauchi, Y., Tsuji, Y., Satoh, S., Minoura, H., Murakami, K., Okuno, A., Inukai, K., Asano, T., Kaburagi, Y., Ueki, K., Nakajima, H., Hanafusa, T.,
Matsuzawa, Y., Sekihara, H., Yin, Y., Barrett, J. C., Oda, H., Ishikawa, T., Akanuma, Y., Komuro, I., Suzuki, M., Yamamura, K., Kodama, T., Suzuki, H., Yamamura, K., Kodama, T., Suzuki, H., Koyasu, S., Aizawa, S., Tobe, K., Fukui, Y., Yazaki, Y., and Kadowaki, T. (1999). Increased insulin sensitivity and hypoglycaemia in mice lacking the p85 alpha subunit of phosphoinositide 3-kinase. Nat. Genet. 21, 230-235.

Tonstad, S., Butler, T., Yan, R., and Fraser, G. E. (2009). Type of vegetarian diet, body weight, and prevalence of type 2 diabetes. Diabetes Care 32, 791-796.

Unoki, H., and Yamagishi, S. (2008). Advanced glycation end products and insulin resistance. Curr. Pharm. Des. 14, 987-989.

Vessal, G., Akmali, M., Najafi, P., Moein, M. R., and Sagheb, M. M. (2010). Silymarin and milk thistle extract may prevent the progression of diabetic nephropathy in streptozotocin-induced diabetic rats. Ren. Fail. 32, 733-739.

Vítek, L., Jirsa, M., Brodanová, M. Kaláb, M., Mareček, Z., Danzig, V., Novotný, L., and Kotal, P. (2002). Gilbert syndrome and ischemic heart disease: a protective effect of elevated bilirubin levels. Atherosclerosis 160, 449-456.

Vítek, L., Malíková, I., Kvasnička, J., Benáková, H., and Novotný, L. (2007a). Relationship between serum bilirubin and markers of inflammation and oxidative stress. J. Gastroenterol. Hepatol. 22, A235A235.

Vítek, L., Novotný, L, Šperl, M., Holaj, R., and Spáčil, J. (2006). The inverse association of elevated serum bilirubin levels with subclinical carotid atherosclerosis. Cerebrovasc. Dis. 21, $408-414$.
Vítek, L., and Ostrow, J. D. (2009). Bilirubin chemistry and metabolism; harmful and protective aspects. Curr. Pharm. Des. 15, 2869-2883.

Vítek, L., and Schwertner, H. A. (2007b) The heme catabolic pathway and its protective effects on oxidative stressmediated diseases. Adv. Clin. Chem. 43, 1-57.

Wegiel, B., Gallo, D., Csizmadia, E., Roger, T., Kaczmarek, E., Harris, C., Zuckerbraun, B. S., and Otterbein, L. E. (2011). Biliverdin inhibits Toll-like receptor-4 (TLR4) expression through nitric oxide-dependent nuclear translocation of biliverdin reductase. Proc. Natl. Acad. Sci. U.S.A. 108, 18849-18854.

Won, K. C., Moon, J. S., Eun, M. J., Yoon, J. S., Chun, K. A., Cho, I. H., Kim, Y. W., and Lee, H. W. (2006). A protective role for heme oxygenase1 in INS- 1 cells and rat islets that are exposed to high glucose conditions. J. Korean Med. Sci. 21, 418-424.

Wu, B. J., Chen, K., Barter, P. J., and Rye, K. A. (2012). Niacin inhibits vascular inflammation via the induction of heme oxygenase-1. Circulation 125, 150-158.

Wu, T. W., Fung, K. P., and Yang, C. C. (1994). Unconjugated bilirubin inhibits the oxidation of human low density lipoprotein better than Trolox. Life Sci. 54, 477-481.

Wu, Y., Li, M., Xu, M., Bi, Y., Li, X. Chen, Y., Ning, G., and Wang, W. (2011). Low serum total bilirubin concentrations are associated with increased prevalence of metabolic syndrome in Chinese. J. Diabetes 3 , 217-224.

Yamagishi, S. I., Maeda, S., Matsui, T., Ueda, S., Fukami, K., and Okuda, S. (2011). Role of advanced glycation end products (AGEs) and oxidative stress in vascular complications in diabetes. Biochim. Biophys. Acta. doi:10.1016/j.bbagen.2011.03.014 [Epub ahead of print].

Yasuda, M., Kiyohara, Y., Wang, J. J., Arakawa, S., Yonemoto, K., Doi, Y., Ninomiya, T., and Ishibashi, T. (2011). High serum bilirubin levels and diabetic retinopathy: the Hisayama Study. Ophthalmology 118, 1423-1428.

Yoshino, S., Hamasaki, S., Ishida, S., Kataoka, T., Yoshikawa, A., Oketani, N., Saihara, K., Okui, H., Shinsato, T., Ichiki, H., Kubozono, T., Kuwahata, S., Fujita, S., Kanda, D., Nakazaki, M., Miyata, M., and Tei, C. (2011). Relationship between bilirubin concentration, coronary endothelial function, and inflammatory stress in overweight patients. J. Atheroscler. Thromb. 18, 403-412.

Conflict of Interest Statement: The author declares that the research was conducted in the absence of any commercial or financial relationships that could be construed as a potential conflict of interest.

Received: 11 January 2012; accepted: 15 March 2012; published online: 03 April 2012.

Citation: Vitek L (2012) The role of bilirubin in diabetes, metabolic syndrome, and cardiovascular diseases. Front. Pharmacol. 3:55. doi: 10.3389/fphar.2012.00055

This article was submitted to Frontiers in Drug Metabolism and Transport, a specialty of Frontiers in Pharmacology. Copyright (c) 2012 Vitek. This is an open-access article distributed under the terms of the Creative Commons Attribution Non Commercial License, which permits non-commercial use, distribution, and reproduction in other forums, provided the original authors and source are credited. 